\title{
DESAPROPRIAÇÃO NA PROPRIEDADE INTELECTUAL APLICADA AO DIREITO AUTORAL
}

\section{EXPROPRIATION ON INTELLECTUAL PROPERTY APPLYING IT TO COPYRIGHT}

\author{
Nivaldo dos Santos ${ }^{12}$ \\ Doutor em Direito \\ Universidade Federal de Goiás - Goiania (GO) - Brasil \\ e \\ Ana Carolina Almeida Di Nápoli ${ }^{3}$ \\ Estudante do Curso de Direito \\ Universidade Federal de Goiás - Goiania (GO) - Brasil
}

RESUMO: 0 presente artigo tem por objetivo abordar aspectos controversos que tangem à propriedade autoral. Após breve retrospecto da evolução histórica do instituto da propriedade, discute-se uma de suas maiores inovações, a Função Social da Propriedade, trazida pela nova constituição, prevista no art. $5^{\circ}$, XXIII: “a propriedade atenderá sua função social"; aplicando-a ao direito autoral. Aproveita-se para discutir a questão da desapropriação no que diz respeito a este tipo de propriedade intelectual, caso sua função social não seja cumprida. Tendo em vista toda a evolução de dado princípio, bem como a "mens legis" da Constituição Cidadã de 1988, fundamentada no princípio da dignidade da pessoa humana; cujos objetivos primordiais são a promoção do bem-estar de todos e o desenvolvimento nacional.

Palavras-chave: Propriedade intelectual. Função social. Desapropriação.

ABSTRACT: This article aims to address controversial issues that concern the copyrighted. After a brief review of the historical evolution of the institution of property, discusses one of his greatest innovations, the Social Function of Property, brought by the new Brazilian constitution provided for in art. 5, XXIII: "pro-

${ }^{1}$ Professor da Universidade Federal de Goiás e da Pontifícia Universidade Católica - GO. Coordenador Rede Estadual de pesquisa em Propriedade Intelectual e Transferência de Tecnologia - REPPITTEC - FAPEG - GO. Pesquisa realizada na Pro-Reitoria de Pós-graduação, no Programa de Pós-graduação Stricto Sensu em Direito. E-mail: nivaldo.santos@ pesquisador.cnpq.br.

${ }^{2}$ Esta pesquisa recebeu fomento dos seguintes órgãos: CNPq, FAPEG, CAPES e FUNAPE.

${ }^{3}$ Aluna do $6^{\circ}$ período da Faculdade de Direito da Universidade Federal de Goiás - UFG e pesquisadora voluntária. Estagiária do Ministério Público Estadual de Goiás. E-mail: ana_a_napoli@hotmail.com. 
perty must fulfill its social function", applying it to copyright. The opportunity to discuss the issue of expropriation with regard to this type of intellectual property, if its social function is not fulfilled. Considering the whole evolution of data principle and the "mens legis" citizen of the Constitution of 1988, based on the principle of human dignity; whose primary objectives are to promote the welfare of all and national development.

Key Words: Intellectual property. Social function. Expropriation.

\section{INTRODUÇÃO}

As normas constitucionais apresentam a propriedade, não mais como um direito individual nem como uma instituição do Direito Privado. Tendo em vista toda a evolução de dado princípio, bem como a "mens legis" da Constituição cidadã de 1988, fundamentada no princípio da dignidade da pessoa humana; cujos objetivos primordiais são a promoção do bem-estar de todos e o desenvolvimento nacional.

Neste contexto, o presente artigo tem por objetivo geral abordar os aspectos controversos que tangem à propriedade autoral. No qual será discutida a questão da desapropriação no que diz respeito a este tipo de propriedade intelectual, caso sua função social não seja cumprida.

Os objetivos específicos são os de, após breve retrospecto da evolução histórica do instituto da propriedade, discutir-se uma de suas maiores inovações, a Função Social da Propriedade, trazida pela nova constituição, prevista no art. $5^{\circ}$, XXIII: “a propriedade atenderá sua função social” eaplicá-la ao direito autoral.

A metodologia empregada no artigo é a revisão bibliográfica e a interpretação das leis ordinárias sob a ótica da constitucionalização do Direito Privado no contexto da Sociedade da Informação.

\section{Evolução Histórica da Propriedade em Geral e o direito do autor}

Segundo Pereira $(2003)^{4}$, pode-se entender que a propriedade é fenômeno espontâneo, decorrente da necessidade de subsistência do ser humano, sendo posteriormente regulado a fim de possibilitar a convivência social pacífica.

4PEREIRA,Caio Mário da Silva. Instituições de Direito Civil, v. III. Rio de Janeiro: Forense,2003, p. 62. 
Embora, ordinariamente, a propriedade esteja vinculada a uma ideia de exclusividade, de individualidade, convém ressaltar que nem sempre foi assim. Aliás, basta remetermo-nos a um olhar retrospectivo para percebemos que, tal instituição fora criada não com fins individuais, mas sim coletivos.

Conforme Gilissen $(2001)^{5}$, os povos arcaicos, sem escrita, se quer tinham propriedade imobiliária, vez que eram nômades, contudo, o que possuíam, por exemplo, o rebanho, era de posse da comunidade; era uma pertença que dizia respeito não ao indivíduo, mas à linhagem. Aos poucos, com a sedentarização do grupo, cada clã se fixou em uma dada terra, essa por sua vez, revestida de caráter sagrado, e, por consequente, inalienável.

Convém ressaltar: as propriedades tanto móvel (rebanho), quanto imóvel (terras em que se fixaram), foram desenvolvidas em prol não de um indivíduo frente a outro: o objetivo primordial, não era ter mais que o outro, era simplesmente, garantir algo para o todo. Isso, porque o indivíduo neste estágio não tinha direito algum; existia enquanto membro do clã; isto é, não havia esta consciência individual que os diferenciava uns dos outros.

A instituição "propriedade" fora inicialmente desenvolvida com uma feição coletiva; em prol do interesse social, de subsistência frente à própria natureza ou mesmo frente a outras comunidades.

A propriedade só foi sendo revestida de caráter individual, posteriormente, ao passo em que houve o crescente domínio da natureza, bem como a tomada de consciência dos sujeitos frente aos outros, possibilitando a apropriação individual.

Com destaque à propriedade romana sob tutela da figura do "Pater Familias", autoridade máxima; completa e exclusiva, que o compara por vezes à soberania de um Estado sobre seu território. Do ponto de vista do direito, ele é o senhor de seus bens: os usa como bem quiser. Indo ao encontro, tempos depois, ao ideário liberal, expresso no CodeCivil francês, em que se concebe o direito de propriedade como a relação entre uma pessoa e uma coisa, de caráter absoluto.

Visão esta, que muitos insistem em manter, sobretudo no âmbito da propriedade autoral, cujo epicentro são, justamente, os “Direitos do autor"; sobrepondo, na maioria dos casos, os interesses individuais em detrimento dos sociais. Apesar das inúmeras transformações pelas quais tem passado a instituição pro-

${ }^{5}$ GILISSEN, John. Introdução histórica ao direito. (trad. de A.M. Botelho Hespanha e I.M. Macaísta Malheiros). Lisboa: Fundação CalousteGulbenkian, 1995 apud GINZBURG, Carlo. Olhos de madeira - nove reflexões sobre a distância. São Paulo: Companhia das Letras, 2001, p. 57. 
priedade, bem como, apesar da Lei Maior de nosso ordenamento caminhar em sentido contrário.

Em uma época em que mesmo a doutrina civilista já se encontra mais aberta a uma interpretação/aplicação do direito que se preocupe com as normas constitucionais, a doutrina autoralista apenas faz referências superficiais ao direito constitucional. Assim, questiona-se, por que afinal, o direito constitucional costuma ser negligenciado em questões de direito autoral? Vez que a CF/88 prevê que a propriedade deverá atender sua função social, por que não falar em função social da propriedade intelectual?

\section{A Função Social na Propriedade Intelectual, particularmente no Direito do Autor}

Diretamente derivado dos direitos individuais, resultado das controvérsias ocorridas no século XVIII, em decorrência dos movimentos humanistas e da Revolução Francesa, o Direito do Autor, ainda que alguns autores reconheçam traços de sua existência já na Antiguidade, tem suas raízes reconhecidas nos privilégios editoriais da Inglaterra, tendo como base legal o Copyright Act, de 1709. Pertencente ao âmbito do Direito Privado, busca a regulação das relações jurídicas decorrentes das manifestações pessoais da criatividade e dons artísticos humanos, que podem ser economicamente utilizados (GUERREIROS, 2007) ${ }^{6}$.

Trata-se de um Direito Especial, que se subdivide em direito moral e direito patrimonial. Segundo Bittar ${ }^{7}$ (2011):

As relações regidas por esse Direito nascem com a criação da obra, exsurgindo, do próprio ato criador, direitos respeitantes à sua face pessoal (como os direitos de paternidade, de nominação, de integridade da obra) e, de outro lado, com sua comunicação ao público, os direitos patrimoniais (distribuídos por dois grupos de processos, a saber, os de representação e os de reprodução da obra, como, por exemplo, para as músicas, os direitos de fixação gráfica, de gravação, de inserção em fita, de inserção em filme, de execução e outros). (grifo nosso)

${ }^{6}$ GUERREIROS JUNIOR, Nehemias. O direito autoral no show bussiness: tudo o que você precisa saber. 3. ed. Rio de Janeiro: Gryphus, 2005,p. 47.

${ }^{7}$ BITTAR, Carlos Alberto. Direito de autor. 3 ed. Rio de Janeiro: Forense Universitária, 2001, p. 8. 
Com relação ao primeiro aspecto: "são vínculos perenes que unem o criador à sua obra, para a realização da defesa de sua personalidade (...) esses direitos nascem com a criação da obra, manifestando-se alguns (como direito inédito) com a simples materialização, ou seja, com a sua inserção na ordem fática, e produzindo efeitos por toda a existência” (BITTAR $\left.{ }^{8}, 2001\right)$, estão relacionados à proteção da personalidade do criador da obra. Já o aspecto patrimonial, visa regular as relações jurídicas da utilização econômica das obras intelectuais; concedendo ao autor, criador e proprietário, amplos poderes sobre sua propriedade.

Contudo, a ideia de propriedade definida como direito subjetivo, absoluto, baseado apenas nos interesses do proprietário não mais se justifica na ordem jurídica nacional, tendo em vista a previsão Constitucional da função social que se manifesta na própria configuração estrutural do direito de propriedade, pondo-se como elemento qualificante na predeterminação dos modos de aquisição, gozo e utilização dos bens:

0 regime Jurídico da propriedade tem seu fundamento na Constituição. Esta garante o direito de propriedade, desde que este atenda sua função social. Se diz: é garantido o direito de propriedade (art. $5^{\circ}, \mathrm{XXII}$ ), e a propriedade atenderá a sua função social ( $\operatorname{art} .5^{\circ}$, XXIII), não há como escapar ao sentido de que só garante o direito da propriedade que atenda a função social. A própria Constituição dá consequência a isso quando autoriza a desapropriação, com pagamento mediante título, de propriedade que não cumpra sua função social (art. 182, §4 ${ }^{\circ}$ e 184)(...). (SILVA, 2012) ${ }^{9}$

Esse conjunto de normas constitucionais deixa claro que a propriedade, atualmente, não pode mais ser considerada como um direito individual nem como instituição do Direito Privado. Conforme o ilustre constitucionalista José Afonso da Silva: a propriedade deveria ser prevista apenas como uma instituição da ordem econômica, como nas Constituições da Itália (art. 42) e de Portugal (art. 62). De tal forma que, embora prevista entre os direitos individuais, ela não poderá mais ser considerada puro direito individual, relativizando-se seu conceito e significado, conforme os ditames da Justiça Social. 
Neste sentido, é importante que se esclareça que a função social passa a constituir um princípio ordenador da propriedade privada e fundamento da atribuição desse direito, de seu reconhecimento e da sua garantia mesma, incidindo sobre o seu próprio conteúdo; vez que se enfrenta uma tendência persistente de reduzir o direito autoral a um monopólio que não carece de qualquer justificação em termos sociais.

Em qualquer ramo do direito, nos diversos tipos de propriedade, a função social deve ser buscada; a partir de tal princípio, introduziu-se, na esfera interna da propriedade, um interesse em contraposição ao do proprietário: o social. E, no que diz respeito à propriedade autoral, não seria diferente.

Assim, tem-se o Direito Autoral não mais como uma espécie de soberania; na medida em que é protegido porque e enquanto contribui para o progresso social, vez que nenhum instituto é consagrado se dele não derivar vantagem social. Logo, o direito autoral está sujeito a todas as determinações finalísticas coletivas que a Constituição exprime; deve estar a serviço da cultura, da informação, da comunicação social, do ensino e etc.

Segundo, Wachowicz ${ }^{10}$ (2013):

Em qualquer caso, há que ter presente que os limites são constitutivos do direito autoral, exatamente nos mesmos termos e com a mesma dignidade das regras atributivas de poderes. O direito autoral é, como todos os direitos, a situação de vantagem resultante de um complexo de poderes e deveres que a constituem.

Por um lado a Constituição ampara os direitos autorais, conferindo poderes aos autores e conexos, elencado em três incisos do art. $5^{\circ}$. No inciso XXVII, preceitua que "Aos autores pertence o direito exclusivo de utilização, publicação ou reprodução de suas obras, transmissível aos herdeiros pelo tempo que a lei fixar”. No inciso XXVIII, tem-se: “(...) são assegurados nos termos da lei: a proteção às participações individuais em obras coletivas e à reprodução da imagem e voz humanas, inclusive nas atividades desportivas; o direito de fiscalização do aproveitamento econômico das obras que criarem ou de que participarem aos criadores, aos intérpretes e às respectivas representações sindicais e associativas".

${ }^{10}$ WACHOWICZ, Marcos. A revisão da lei brasileira de direitos autorais. 2010. Disponível em: <http://www. direitoautoral. ufsc.br/gedai/wp-content/uploads/livros/ GedaiUFSC_Livro Estudos DirAutor_vfinal.pdf>. Acesso em 30 mai. 2013 , p. 39. 
Já no inciso XXIX, mostra-se o caráter binário que tange as obras intelectuais:

(...) a lei assegurará aos autores de inventos industriais privilégio temporário para sua utilização, bem como proteção às criações industriais, à propriedade das marcas, aos nomes de empresas e a outros signos distintivos, tendo em vista o interesse social e o desenvolvimento tecnológico e econômico do País. (grifo nosso)

De tal modo, convém ressaltar os interesses coletivos no mesmo âmbito temático, que também são tutelados pelo Estado, remetendo a este o dever de garantir o acesso aos bens culturais:

art. $5^{\circ}$, XIV - é assegurado a todos o acesso à informação e resguardado o sigilo da fonte, quando necessário ao exercício profissional.

Art. 215. O Estado garantirá a todos o pleno exercício dos direitos culturais e acesso às fontes da cultura nacional, e apoiará e incentivará a valorização e a difusão das manifestações culturais

Art. 205. A educação, direito de todos e dever do Estado e da família, será promovida e incentivada com a colaboração da sociedade, visando ao pleno desenvolvimento da pessoa, seu preparo para o exercício da cidadania e sua qualificação para o trabalho. (grifo nosso)

Fica evidente assim, o interesse maior do Estado; que vai além de simplesmente proteger o autor, de modo a prestigiar também o interesse coletivo. Até porque, o Estado, enquanto ente dotado de personalidade jurídica existe justamente para promover a estruturação da sociedade e o bem comum nele inseridos, advindo daí, a função social a ele inerente (VITALIS, 2006) ${ }^{11}$.

Há um desvio muito frequente hoje, que leva a invocar situações diversas, como, por exemplo, a facilidade de compartilhamento de arquivos pela internet, pirataria, dentre outros, que, ordinariamente, levam a concluir pela necessidade de reforço do direito autoral.

Contudo, este unilateralismo não se justifica. Como dito anteriormente, tra-

${ }^{11}$ VITALIS, Aline. A função social dos direitos autorais: uma perspectiva constitucional e os novos desafios da sociedade de informação. In: BRASIL, Ministério da Cultura. Direito autoral. Brasília: Ministério da Cultura, 2006, s/p. 
ta-se, de um direito com interesses múltiplos e relações bifurcadas: de uma lado a relação obra-autor (propriedade-proprietário), amparada pelo Estado, em prol de uma outra relação: a da obra-sociedade (função social da propriedade).

Verifica-se assim, um conflito a nível constitucional: de uma parte o autor, que busca proteção à sua obra, sendo esta, de certo modo, vinculada à própria pessoa de seu autor, visto que fora concebida graças a este; e de outro, tem-se direito da sociedade ao acesso à informação, cultura e educação, de fundamental importância para o desenvolvimento da nação.

Conforme destaca Vitalis ${ }^{12}$ (2006):

(...) verificou-se um conflito entre a necessidade do progresso da educação e da cultura como fatores fundamentais para o desenvolvimento da nação e a imperatividade da concessão da proteção legal às criações intelectuais surgidas em seu contexto, exatamente como estímulo para a produção de obras de engenho pelos respectivos nacionais. 0 choque de interesses é evidente: 0 interesse do autor (individual) volta-se para a proteção e retribuição econômica de sua obra, ao passo que o da coletividade corresponde à fruição dessa mesma obra.

Sem dúvida, o direito ao acesso à informação e à cultura é o que mais se contrapõe ao direito do autor, principalmente na sociedade da informação, em que tem-se a Internet como um dos principais instrumentos de divulgação do saber, tornando o acesso aos bens culturais mais acessível e, por consequente, mais democrático.

Nesse sentido, há que se atentar também para as questões relativas à "inclusão digital”, que ademais do maior acesso à informação e à cultura, acaba por gerar também uma maior liberdade na criação e na fruição de bens intelectuais, fomentando a criação de novas obras.

Percebe-se assim, que o poder de difusão desse novo meio de comunicação compensa as vicissitudes autorais, sendo os benefícios para a humanidade muito maiores que as perdas autorais, remetendo-nos à necessidade de flexibilização do direito de autor, de modo a compatibilizar o sistema legal intelectual com as novas realidades impostas pela sociedade informacional globalizada.

Uma das grandes potencialidades trazidas pela informática, que não podemos

${ }^{12}$ Idem, p. 205. 
deixar de tratar, ainda que de maneira breve, diz respeito à digitalização do material cultural. Se por um lado, possibilita maior acesso, por tornar os custos de reprodução das obras mais baratos; por outro, o restringe, vez que tais obras só são consumidas a partir do uso de aparato tecnológico que, para grande maioria da população brasileira, ainda é promessa.

Resumindo, só consumiria a obra digital aqueles que tivessem acesso à tecnologia, o que resultaria na perpetuação de um ciclo vicioso: apenas um grupo seleto, com acesso à tecnologia, teria ampliado o seu acesso aos bens culturais. Assim, continuaríamos a não alcançar a "mens legis" de nossa Constituição, que prega a democracia, visa a redução das desigualdades sociais e a promoção do bem de todos.

Contudo, considerando, as diversas políticas públicas em prol da inclusão digital e, levando em conta também o exponencial crescimento do acesso à tecnologia, suponhamos (sendo bem otimista) que, em algumas décadas, o problema do acesso digital seja sanado. Ainda sim, haveria outras problemáticas, como bem ressalta Cohen apud Mizukami ${ }^{13}$ (2007):

Um consumidor acessa um website e compra um e-book. No ato da compra, assina um extenso e detalhado contrato eletrônico de adesão, sem qualquer possibilidade de negociação de termos. 0 contrato fixa uma série de restrições de acesso e de uso do bem adquirido, com graus de permissibilidade variáveis de contrato a contrato. Pode determinar, por exemplo, que o consumidor tem o direito de acessar o e-book apenas cinco vezes; que não pode usar um programa, text-to-speech para converter o texto em voz, que não pode fazer cópias de qualquer palavra do texto; que não pode imprimi-lo; que não pode utilizá-lo por mais de cinco dias etc. As possibilidades são inúmeras, e o controle muito maior do que a de obras adquiridas por meio não digital. Além disso, registros referentes à frequência e forma do uso do conteúdo pelo consumidor são enviados a uma base de dados remota. 0 consumidor visualizou quantas páginas do livro? Por quanto tempo deixou o arquivo aberto? Quantas vezes acessou o arquivo? Selecionou e marcou algum trecho do texto? As possibilidades são igualmente inúmeras, e tão invasivas quanto a implementação do sistema de

\footnotetext{
${ }^{13}$ MIZUKAMI, Pedro Nicoletti. Função Social da Propriedade Intelectual: compartilhamento de arquivos e direitos autorais na CF/88. São Paulo: Malheiros, 2005, p. 151/152.
} 
DRM permitir. Como diz Cohen, esses sistemas colocam em risco o direito de se ler anonimamente.

Com base no breve exposto, já se tem ideia de que esta questão da digitalização de obras culturais está longe de ser a solução para os problemas entre os direitos do autor e os direitos sociais, principalmente, no que tange ao direito de acesso ao conhecimento, à informação e à cultura.

A Declaração de Princípios da Cúpula Mundial sobre a Sociedade da Informação, de 2003, em seu terceiro capítulo, sobre "acesso à informação e ao conhecimento", estabelece, de modo geral, que todos devem ter acesso à informação, às ideias e ao conhecimento; nesse sentido, prega a eliminação de barreiras ao acesso equitativo à informação, visto que acredita ser fundamental promover a produção de conteúdos, bem como sua acessibilidade, independentemente de propósitos educativos, científicos, culturais ou recreativos, já em seu oitavo capítulo ${ }^{14}$.

De tal modo, verifica-se a tendência apontada pela Declaração de Princípios da Cúpula Mundial sobre a Sociedade da Informação no sentido da prevalência do direito de acesso à informação e à cultura sobre o direito do autor, em especial quando estiverem em jogo interesse sociais, econômicos e culturais de um povo.

Pinto $^{15}$ (2013) acrescenta um interessante argumento à prevalência dos direitos sociais: segundo este, por óbvio, o direito autoral deve ser respeitado conforme elencado na Constituição Federal, resguardando os direitos do autor sob sua criação. Contudo, ressalta que existem limites para todos os princípios constitucionais, quando este afete o maior de todos os princípios: o da dignidade da pessoa humana. Neste sentido, o referido autor continua:

Um ser social que não teve acesso aos meios educacionais nunca será um cidadão por completo, estará sempre à margem da sociedade, tendo sua dignidade humana suprimida. Neste ponto, devemos analisar a função social da propriedade intelectual, que mesmo protegida pelo ordenamento jurídico, deve sim cumprir um papel social para o desenvolvimento intelectual de todos os cidadãos.

\footnotetext{
${ }^{14}$ Para informações sobre a Cúpula Mundial sobre a Sociedade da Informação, conferência fundamental para a discussão dos temas desta dissertação, o web site da UIT- União Internacional de Telecomunicações é o repositório oficial. Disponível em: <http://www.itu.int/wsis/>. Acesso em 30 mai. 2013.

${ }^{15}$ PINTO, Ricardo de Oliveira. A função social da propriedade intelectual. In: Âmbito Jurídico, Rio Grande, v. 63. Disponível em:<http://www.ambitojuridico.com.br/site/index.php?n_link=revista_artigos_leitura\&tartigo_id=6066>. Acesso em 30 mai. 2013.
} 
Em análise não só das normas internas, mas também de tratados de que o Brasil é signatário, com destaque para a Declaração dos Direitos Universal de Direitos Humanos, que em seu art. XXVII, tem-se:

1.Toda pessoa tem o direito de participar livremente da vida cultural da comunidade, de fruir as artes e de participar do processo científico e de seus benefícios. 2. Toda pessoa tem direito à proteção dos interesses morais e materiais decorrentes de qualquer produção científica, literário ou artística da qual seja autor $^{16}$.

À primeira vista, pode-se acreditar que se trata de um artigo conflituoso, em que se tem uma contraposição de preceitos. Entretanto, após maior reflexão, percebe-se que se trata de cláusula geral que objetiva nortear as legislações nacionais rumo a um equilíbrio entre a proteção dos direitos individuais e a função social da mesma.

Isto porque, todo direito posto deve servir simultaneamente o interesse público e o interesse privado. 0 atual enriquecimento dos poderes privados faz-se à mercê do interesse coletivo; quando a solução está, pelo contrário, na busca do necessário equilíbrio, de modo que aqueles interesses não se digladiem, mas convivam harmoniosamente na máxima satisfação de suas finalidades.

Sobre o equilíbrio entre o direito à cultura e o direito de autor, o então Ministro da Cultura, Gilberto Gil, assim se expressou em seu discurso no $1^{\circ}$ Congresso Internacional da Propriedade Intelectual, realizado em março de 2003, São Paulo:

(...) é evidente que os interesses econômicos neste ramo de direito são consideráveis. No entanto, é importante salientar que os direitos de propriedade intelectual sempre se pautaram pela busca de um equilíbrio entre os direitos do criador, que deve receber uma justa compensação por seu esforço criador, e o conjunto da sociedade, que deve ter garantido o seu direito de acesso à informação, à tecnologia e ao patrimônio cultural comum. Tenho afirmado que não cabe ao Estado fazer cultura, mas, sim, proporcionar condições necessárias para a criação e a produção de bens culturais, sejam eles artefatos ou mentefa${ }^{16} \mathrm{ONU}$. Declaração Universal dos Direitos Humanos, 10 de dezembro de 1948. Disponível em: <http://portal.mj.gov.br/
sedh/ct/legis_intern/ddh_bib_inter_universal.htm>. Acesso em 30 mai. 2013. 
tos. 0 acesso à cultura é um direito básico de cidadania, assim como o direito à educação, à saúde, à vida num ambiente saudável. Neste sentido, reveste-se da maior importância - no âmbito dos direitos autorais - a busca de uma legislação equilibrada e que tenha como objeto principal a efetiva proteção dos criadores nacionais ${ }^{17}$.

Prol equilíbrio, lecionaWachowicz (2013), ao defender que o direito autoral deve ser exercido de maneira que a vantagem pessoal se combine com a social. Segundo esta, sabendo-se que os interesses fundamentais em jogo são o interesse privado do autor e o interesse coletivo no benefício social resultante da obra protegida, há que se buscar a medida ótima de satisfação desses interesses, portanto, o ponto de equilíbrio, sem preconceitos a partido num sentido ou noutro.

Havendo conflito, o esquema da ordem jurídica não se encontra num "ou tudo ou nada", mas pela possível conciliação. Há que procurar as vias pelas quais os direitos recebam a máxima satisfação, provocando o menor sacrifício de outros direitos igualmente protegidos.

Questiona-se, assim, como os desenvolvimentos intelectuais, impulsionados pela necessidade de lucro para a sua subsistência poderiam interagir com as necessidades sociais e manter seu caráter financeiro? Como conciliar tais perspectivas?

Indubitavelmente, há que se proteger as criações intelectuais, propiciando ao autor retirar os proventos correspondentes da sua criação, inclusive como meio de incentivo para a produção de novas obras. Contudo, esta proteção deve sofrer restrições sempre que sirva de empecilho à difusão do conhecimento e disseminação da cultura. Isso porque, segundo com Comparato ${ }^{18}$ (2013):

(...) quando a propriedade não se apresenta, concretamente, como uma garantia da liberdade humana, mas, bem ao contrário, serve de instrumento ao exercício de poder sobre outrem, seria rematado absurdo que se the reconhecesse o estatuto de direito humano, com todas as garantias inerentes a essa condição.

\footnotetext{
${ }^{17} \mathrm{GIL}$, Gilberto. Discurso no $1^{\circ}$ Congresso Internacional da Propriedade Intelectual, realizado em São Paulo em 31. mar.2003. Disponível em: <http://www2.cultura.gov.br/scripts/discursos.idc?codigo=83>. Acesso em 30 mai. 2013. ${ }^{18}$ COMPARATO, Fábio Konder. Direitos e deveres fundamentais em matéria de propriedade. Revista do Ministério Público do Estado do Rio de Janeiro, n. 7, p. 73-88, 1998. p. 88.
} 
Reforça-se tal ideia, a partir do novo texto constitucional, em que passou a vigorar um novo modelo de propriedade, levando em conta os valores sociais, norteadores do Estado Democrático de Direito, fincado na dignidade da pessoa humana.

Como objetivos constitucionais tem-se a construção de uma sociedade justa e solidária, fazendo com que não mais prevaleça único e exclusivamente o interesse individual do proprietário. Conforme Vitalis (2006), a propriedade passou a ter como elemento integrativo de seu conteúdo a função social, sem a qual o direito de propriedade não merecerá sequer tutela jurídica, transfigurando-se em um instrumento para a realização do projeto constitucional.

Por consequente, o direito autoral deve ser, assim, um instrumento de desenvolvimento que venha ampliar políticas de difusão de cultura, promovendo a educação e o conhecimento, indo ao encontro dos anseios sociais, garantido o bem estar de todos e o desenvolvimento das potencialidades dos cidadãos, de modo que a função social da propriedade não seja apenas mais uma norma pragmática de nossa Constituição e que, esta, por sua vez, não seja apenas uma folha de papel.

\section{A Desapropriação da Propriedade Intelectual, particularmente o Direito do Autor}

Diante do exposto, tendo em vista que a função social da propriedade também deve ser levada em conta em termos autorais, e que, segundo diversos autores, dentre eles os já citados Silva (2012) e Vitalis (2006), só merecerá tutela a propriedade que cumprir sua função social, como proceder em termos autorais? Caberá desapropriação de obras intelectuais por descumprimento de sua função social, em prol do interesse público?

De pronto, convém ressaltar que o princípio da função social de modo algum autoriza suprimir a instituição da propriedade privada. Visto que, a desapropriação, não se dará por qualquer banalidade ou vontade estatal, aos moldes das antigas Monarquias Absolutistas; aquela só ocorrerá se presentes uma série de requisitos previstos em lei, conforme inciso XXIV, art.5, CF: “a lei estabelecerá para desapropriação por necessidade ou utilidade pública, ou interesse social, mediante justa e prévia indenização em dinheiro, ressalvada os casos previstos nesta Constituição". 
Ressalte que, apesar do fundamento teórico da desapropriação ser a supremacia do interesse coletivo sobre o individual, quando incompatíveis estes; também há a preocupação com o direito individual, ao prever a justa indenização.

Sendo estabelecidos os casos de utilidade pública nas alíneas do Decreto Lei $\mathrm{n}^{\circ}$ 3.365, de 1941, reforçadas pela Lei 6.602, de 1978, bem como pela Lei 9785 , de 1999; bem como os casos de desapropriação por interesse social, elencados pela Lei Federal $n^{\circ}$ 4.132, de 1962. Sem deixar de lado a Lei Federal $n^{\circ} 10.257$ (Estatuto Urbano), de 2001, que no artigo $4^{\circ}$, inciso V, alínea "a" também prevê como instituto jurídico e político a desapropriação urbana para cumprimento da função social.

Contudo, percebe-se que tais dispositivos ora fazem referência à propriedade rural, fazendo menção à reforma agrária, ora fala-se em propriedade urbana, e pouco (apenas uma vez), fala-se em propriedade intelectual, considerando caso de utilidade pública, para desapropriação, a reedição ou divulgação de obra ou invento de natureza científica, artística ou literária (Decreto Lei $n^{\circ} 3.365$, art. $5^{\circ}$, o). Com base nisto, podemos dizer que é válido desapropriar tais propriedades quando descumprida sua função social?

A desapropriação é um procedimento através do qual o Poder público despoja alguém de uma propriedade e a adquire, fundado em um interesse coletivo. Agora, em se tratando de propriedade autoral, como privar o autor de sua obra, de sua criação, para uns, tida como parte da individualidade do autor?

Segundo Silva (2012, p. 277), a desapropriação não pode ocorrer enquanto o autor da obra estiver vivo, já que conservá-la inédita ou fora de circulação se inclui entre seus direitos morais personalíssimos e inalienáveis.

Outros, quiçá defenderiam que a desapropriação intelectual não seria possível em hipótese alguma visto que a obra é parte do autor, sendo assim, não seria possível apoderar-se de algo que é intrínseco àquele ser.

Contudo, tal argumento não poderá prosperar visto que, o fato de algo vir de algum lugar não implica, necessariamente, que tal coisa seja o próprio ser gerador; muito pelo contrário, o que diferencia criador e criatura, é justamente o fato da criatura ser algo distinto, novo do criador. Sendo assim, porquê não considerá-la independente, uma vez já compartilhada?

Ademais, desapropriar uma obra intelectual não se trata de privar, mas sim de socializar, fazer com que outras pessoas também tenham acesso a determinado bem cultural, de modo a democratizar o acesso aos bens culturais, sem necessitar sem- 
pre do consentimento do autor; fato que concentra demasiado poder em suas mãos, dificultando a difusão do saber e o consequente desenvolvimento cultural do país.

Ainda mais ao levarmos em conta nossa Constituição Cidadã, bem como as novas perspectivas sobre a propriedade, que conforme dito anteriormente, não mais pode ser tida como um direito individual, mas sim, deveria ser vista apenas como instituição do direito econômico, conforme Silva (2012).

Não se trata de privar, visto que para todo o sempre dada obra será vinculada ao seu autor, merecedor de uma justa compensação, o que inclui remuneração e indenização, se for o caso; visto que a maioria das obras são desenvolvidas atreladas à finalidade econômica, até mesmo, de modo a não desestimular a produção dessas obras.

Assim, ao indenizá-los de modo justo (e sobre isso há que ter mais dispositivos legais), garantir-se-ão os direitos individuais dos autores e, ao mesmo tempo, possibilitará a efetivação da função social da propriedade autoral; já que sem dada sanção, a desapropriação será, como dito anteriormente, apenas mais uma norma programática em uma Constituição tida como idealista.

Ademais, nossa Constituição ainda prevê:

Art. 216: constituem patrimônio cultural brasileiro os bens de natureza material e imaterial, tomados individualmente ou em conjunto, portadores de referência à identidade, à ação, à memória dos diferentes grupos formadores da sociedade brasileira, nos quais se incluem: I - as formas de expressão; II- os modos de criar, fazer e viver; III - as criações científicas, artísticas e tecnológicas; IV- as obras, objetos, documentos, edificações e demais espaços destinados às manifestações artístico-culturais; (...). (grifo nosso)

§1: o poder público, com colaboração da comunidade, promoverá e protegerá o patrimônio cultural brasileiro, por meio de inventários, registros, vigilância, tombamento e desapropriação, e de outras formas de acautelamento e preservação. (grifo nosso)

Eis assim, outro fundamento prol intervenção do Estado nas obras protegidas pelo direito autoral que, segundo Carboni ${ }^{19}$ (2013), pode se dar até mesmo na forma de desapropriação, visando o cumprimento do seu dever de zelar

${ }^{19}$ CARBONI, Guilherme C. O direito de autor e seus desafios: os conflitos com a liberdade de expressão, o direito de acesso ao conhecimento, à informação e à cultura e o direito ao desenvolvimento tecnológico. Disponível em: <http: // www.gcarboni.com.br/pdf/G5.pdf>. Acesso em 20 mai. 2013. 
pela proteção do patrimônio histórico brasileiro. Para este, tal interferência deve ter como fundamento e limite a proteção do patrimônio da cultura nacional; sendo os excessos, aí sim, uma violação de direitos autorais.

Isto porque, conforme Silva ${ }^{20}$ (2013), o patrimônio cultural imaterial cumpre uma inestimável função, por tratar-se de poderoso fator de aproximação, intercâmbio e entendimento entre os povos e grupos sociais existentes e de afirmação de sua identidade cultural; tendo um papel fundamental à sadia qualidade de vida das presentes e futuras gerações.

Outrossim, seguindo o raciocínio de tal autora, "esse bem imaterial nasce da intervenção da pessoa humana no meio ambiente, construindo sua identidade e memória enquanto indivíduo e coletividade, para cada povo e nação" (grifo nosso).

Assim, além de ser formador da identidade e memória nacional e, portanto, indissociável de seu povo, podendo ser tido como Patrimônio Cultural; convém ressaltar que tal patrimônio tem natureza jurídica difusa, vez que cultura é algo que não se constrói só; constrói-se em sociedade, a partir da relação dos seres entre si e com o meio ao longo do tempo e, por isso, é de interesse de todos, indistintamente. Independe, inclusive, da época. Neste sentido, Fiorillo e Rodrigues apud Silva (2013):

Está aí, mais uma justificativa da titularidade difusa desse bem que pertence a todos e que, justamente por isso, não comporta um conceito tradicionalista de propriedade, mas, ao contrário, um tipo de domínio preenchido pelos elementos de fruição (uso e gozo do bem objeto de direito) sem comprometimento da sua integridade, para que outros titulares, inclusive os de gerações futuras, possam também exercer, com plenitude, o mesmo direito. Depreende-se do exposto acima, que o patrimônio cultural imaterial deve ser tutelado sob o ponto de vista jurídico ambiental e assegurar o seu acesso aos titulares do presente e do futuro. Daí, a responsabilidade intergeracional como princípio fundamental para a proteção deste bem, devendo-se assegurar a equidade de acesso entre as gerações, a este bem integrante Patrimônio Cultural Imaterial.

\footnotetext{
${ }^{20}$ SILVA, Daisy Rafaela da. Patrimônio Cultural Imaterial: antecedentes e proteção jurídico ambiental. Âmbito Jurídico, Rio Grande, XII, n. 63, abril de 2009. Disponível em:<http://www.ambitojuridico.com.br/site/index.php?n_link=revista_ artigos_leitura\&artigo_id=5931> Acesso em 10 jun. de 2013.
} 
De tal forma, percebe-se que a dimensão pública do direito autoral tem papel preponderante quando se aborda a questão de políticas públicas para a preservação cultural e promoção da diversidade cultural do povo brasileiro. Assim, a desapropriação deverá ocorrer nos casos em que se mostrar necessária à realização do princípio que se põe acima do interesse individual, qual seja: o da dignidade humana, que inclui o direito à cultura e conhecimento.

\section{CONSIDERAÇÕES FINAIS}

Verifica-se, que a legislação brasileira, em termos autorais se mostra bastante displicente com relação à função social da propriedade intelectual; contudo, mesmo sendo a lei infraconstitucional pobre neste sentido, a nova Constituição, com suas normas gerais, supre em partes, tais debilidades, ao permitir uma interpretação ampla com relação à função social da propriedade.

Conclui-se, assim, que o princípio da função social é aplicável também em campo autoral; devendo tal ramo servir não só como instrumento de proteção dos direitos do autor, mas também, como instrumento prol desenvolvimento cultural do país. Para tanto, visando o equilíbrio de interesses, há que sopesar princípios, o que consiste, basicamente em, ora conceder poderes, ora impor restrições.

Sendo, uma importante restrição aos direitos do autor, a função social da propriedade, que não deve ser mais uma norma pragmática em nossa Constituição. Esta deve ir ao encontro dos anseios sociais, garantindo o bem- estar de todos e o desenvolvimento das potencialidades dos cidadãos.

E, como forma importante de resguardar a função social da propriedade, bem como proteger o acesso aos bens culturais imateriais, tem-se a desapropriação, que também se mostra aplicável em termos autorais, com fundamento e limite no interesse social, nos casos em que o interesse público deva prevalecer sobre o interesse individual, o que só poderá ser determinado a partir da análise do caso concreto. 


\section{REFERÊNCIAS}

BITTAR, Carlos Alberto. Direito de autor. 3.ed. Rio de Janeiro: Forense Universitária, 2001.

BRASIL.Constituição Federal.Brasília: Senado Federal, 1988. Disponível em: <http://www.planalto.gov.br/ccivil_03/Constituicao/Constituiçao.htm>. Acesso em:30ago. 2013.

.Lei $n^{\circ}$ 9.279, de 14 de maio de 1996. Regula direitos e obrigações relativos à propriedade industrial.Brasília: Senado Federal, 1996. Disponível em: <http:// www.planalto.gov.br/ccivil_03/leis/19279.htm>. Acesso em: 30 ago. 2013.

CARBONI, Guilherme C. O direito de autor e seus desafios: os conflitos com a liberdade de expressão, o direito de acesso ao conhecimento, à informação e à cultura e o direito ao desenvolvimento tecnológico. Disponível em: <http: //www. gcarboni.com.br/pdf/G5.pdf>. Acesso em: 30 mai. 2013.

COMPARATO, Fábio Konder. Direitos e deveres fundamentais em matéria de propriedade. Revista do Ministério Público do Estado do Rio de Janeiro, n. 7, p. 7388, 1998.

GILISSEN, John. Introdução histórica ao direito. (trad. de A.M. Botelho Hespanha e I.M. Macaísta Malheiros). Lisboa: Fundação CalousteGulbenkian, 1995 apub GINZBURG, Carlo. Olhos de madeira - nove reflexões sobre a distância. São Paulo: Companhia das Letras, 2001.

GUERREIROS JUNIOR, Nehemias. O direito autoral no show bussiness: tudo o que você precisa saber. 3.ed. Rio de Janeiro: Gryphus, 2005.

MIZUKAMI, Pedro Nicoletti. Função Social da Propriedade Intelectual: compartilhamento de arquivos e direitos autorais na CF/88. São Paulo, 2007.

ONU. Declaração Universal dos Direitos Humanos, 10 de dezembro de 1948. Dis- 
ponível em: <http://portal.mj.gov.br/sedh/ct/legis_intern/ddh_bib_inter_universal.htm>. Acesso em: 30 mai. 2013.

PEREIRA,Caio Mário da Silva. Instituições de Direito Civil, v. Ill. 6.ed. Rio de Janeiro: Forense. 2003

PINTO, Ricardo de Oliveira. A função social da propriedade intelectual. In: Âmbito Jurídico, Rio Grande, v. 63. Disponível em: <http://www.ambitojuridico.com.br/ site/index.php?n_link=revista_artigos_leitura\&tartigo_id=6066>. Acesso em: 30 mai. 2013.

SILVA, Daisy Rafaela da. Patrimônio Cultural Imaterial: antecedentes e proteção jurídico ambiental. Âmbito Jurídico, Rio Grande, XII, n. 63, abril de 2009. Disponível em:<http://www.ambitojuridico.com.br/site/index.php?n_link=revista_artigos_leitura\&tartigo_id=5931>.Acesso em: 10 jun. 2013.

SILVA, José Afonso da.Curso de Direito Constitucional. 35.ed. São Paulo: Malheiros, 2012.

VITALIS, Aline. A função social dos direitos autorais: uma perspectiva constitucional e os novos desafios da sociedade de informação. In: BRASIL, Ministério da Cultura. Direito autoral. Brasília: Ministério da Cultura, 2006.

WACHOWICZ, Marcos. A revisão da lei brasileira de direitos autorais. 2010. Disponível em: <http://www.direitoautoral.ufsc.br/gedai/wp-content/uploads/livros/GedaiUfSC_Livro Estudos DirAutor_vfinal.pdf>. Acesso em: 30 ago. 2013. 